Open Access

\title{
Opening up design studio education using blended and networked formats
}

Olga loannou(D)

Correspondence: ioannouolga@ gmail.com; ioannou@central.ntua.gr National Technical University of Athens (NTUA), 95, Sirinon St., 17562, P. Faliro-, Athens, Greece

\begin{abstract}
Design education is based on a model of instruction that encourages open practices such as team work and group revisions. However, interaction in the design studio is usually conditioned by the predetermined hierarchical rapports that exist between tutors and students, while openness is restricted within the physical and temporal confines of the classroom. In this context, conventional design studio layouts run the risk of reproducing the views and norms of the profession without the critical insight or input of the user and the observer. This paper describes the process of redesign of an undergraduate urban design studio with the aim of extending openness from an operational behavior to a holistic attitude towards design. A blended model was used as a means of expanding studio activities while a network structured communications setting sought to promote student connectivity. Communication was expanded to stakeholders and members of the community involved in the project as well as people from other domains in order to broaden the knowledge base of the studio. Online features and additional face-to-face practices were used in a complementary mode because blending was not limited to the adoption of online modalities but also involved the reconsideration of $\mathrm{f} 2 \mathrm{f}$ meetings and the redesign of the studio as a whole. The paper describes the implications the new studio layout has had on the students who attended. Data retrieved from analytics and blog statistics together with the results of a survey conducted upon the studio's completion reveal that even though blending began as a course objective set by tutors, it was the students who did the blending by choosing the degree of their involvement in the various features offered in the layout. This paper also argues that opening up the educational process to blended formats is directly related to the contemporary professional activity by setting a new framework for design practice.
\end{abstract}

Keywords: Design education, Network learning, Blended learning, Open modalities, Evidence of impact

\section{Design studio profile and limitations}

Design Studio (DS) education is considered by many to be signature pedagogy. The term implies that the DS is where 'a professional situation is reproduced in an academic context' (Masdeu \& Fuses, 2017, p. 8). Laurillard (2012, p. 220) also attests to the fact that they are "teaching ideas most likely to develop in very specific subject matter contexts," while Shulman (2005: 52) points to a pervasive type of teaching "that organizes the fundamental ways in which future practitioners are educated for their profession." Shulman further distinguishes three dimensions in signature pedagogy: a surface structure of operational acts of teaching and learning, a deep structure of

(c) The Author(s). 2018 Open Access This article is distributed under the terms of the Creative Commons Attribution 4.0 International License (http://creativecommons.org/licenses/by/4.0/), which permits unrestricted use, distribution, and reproduction in any medium, provided you give appropriate credit to the original author(s) and the source, provide a link to the Creative Commons license, and indicate if changes were made. 
assumptions about how best to impact knowledge and an implicit structure as a set of beliefs, values and attitudes otherwise referred to as the hidden curriculum.

Design education is, in many ways (or at many levels), related to openness; its surface structure welcomes open practices such as group discussions (Parnell, 2001) and direct student-tutor interaction during revisions. It is also a socially active environment of experimentation and collaboration between students. Team work is a most common and highly evaluated practice where students are asked to work together in groups of two or three. Deep structure manifests through the constant negotiation/ confrontation of student design methodology and through the production of design ideas and artifacts and their subsequent evaluation from the tutor(s). Students are often required to present the development of their projects in front of an expert audience and to be openly subjected to criticism from their tutors or other invited guests.

DS is also a perfect model for inculcation, essential for socializing students in a cultivated 'habitus' (Stevens, 1998). It is a transformative pedagogy where students learn about design; they learn to design but they also learn how to become architects and this is what makes DS hidden curriculum an educational setting not only for learning about but also for learning to be (Dutton, 1987). Crowther (2013) further argues that DS is at the same time a physical space; a mode of engagement, and a place of work activity and that in fact it is this particular aspect that the DS attempts to replicate.

However, peer to peer interactivity in the DS is coordinated solely by tutors; students rarely have the opportunity to exchange and discuss matters on their own directly without the presence of a moderator. Revision time, which is otherwise referred to as desk critique, usually lasts approximately half an hour and is mostly private as it involves only the student team and the reviewing tutors. This means that class mates hardly ever have the chance to monitor closely what the others are doing or relate their own work to their peers' projects as there is usually a lack of a framework for the students to be able to share their own material with the others. Moreover, student content retrieved from their previous experiences or their ongoing research is omitted from the studio's curriculum despite the fact that learning, as McClean \& Hourigan (2013) argue, depends upon the individuals' existing knowledge, "against which new information is aligned creating either a deepening of knowledge or leading to previous knowledge being revised" (2013, p. 4).

Furthermore, the dialectical nature of the design studio depends upon the interactivity between its two main protagonists -professors and students- and it is usually conditioned by the rapports of hierarchy that are implicitly imposed by a difference in power (Bachman \& Bachman, 2010; Dutton, 1987). There are two major implications for this: one is that the power relations are being reproduced and the other is that exchange and interaction rarely involve other parties or agents related to the project assignment. Openness is compromised by the seclusion of other actors or stakeholders throughout the design process while the relevance of the projects produced in the end is evaluated and assessed solely by tutors and design professionals. Thus openness in the DS manifests itself mostly as an operational behavior that is concerned with certain practices within the classroom rather than a holistic attitude toward design.

The practice of isolating students from contemporary realities compromises today's ever-changing character of the architectural profession and the increasing complexity of the urban environment. Pete Buchanan (2012) argues that "architectural education is 
still geared to producing the solitary genius, rather than today's collaborator." In the past decades, however, attempts have been made to direct DS practices towards a more open and collaborative setting. Technology advancements, especially the web, played a major part in reconsidering the studio, but new technology was also invented to enable collaboration and virtual communication.

\section{Context: From virtual design studios to blended and networked learning}

Most major changes in the DS have been brought about by the use of computers and the introduction of web related activities to course structure. When Web 1.0 technologies were originally integrated into education during the early 1990's, there was a proliferation of attempts to create the web analogy for the DS, otherwise known as the Virtual Design Studio (VDS) (Pak et al., 2012). The technological possibilities of the time -such as teleconferencing or instant messaging- allowed researchers to conduct DSs between institutions from different continents and time zones (Bradford et al., 1994; Yee, 2001), thus bringing together students from various cultures and making them collaborate (Laiserin, 2002). In the same spirit, computer supported collaborative work (CSCW) practices sought to bridge the physical distance between students from different institutions through technologically advanced hardware, such as Giovanni Birindelli's e-table in ETH or the use of sophisticated software. (Novakova et al., 2012).

In their original version, VDSs replicated the operational status of the traditional DS, but this time, in a different medium; all design processes, such as tutorials and deskcrits, were preserved. Students were still required to work in groups -by now comprised of students from different universities- and provide design solutions and artifacts, physical or virtual. The only difference lay in the fact that tutors experimented with the cohorts' cultural diversity and systematically encouraged structured collaborative practices toward a new type of practitioner with efficient communication skills to handle diversity and design for distant projects. A new understanding of openness was gradually instilled by lifting the communication barriers among institutions, while the ability to bring students together from completely different cultural backgrounds, -despite the complexity of the endeavor,- enriched the educational experience for those involved in the process (Kvan 1997). In addition, VDSs invited students to reconsider the meaning of external sources of knowledge (Griegson, 2004), which was a major step forward in renegotiating the conditions for the construction of knowledge in the DS.

All these examples stem from the intellectual propensity to experiment with new technology, but students were also confronted with the challenging task of working with people they did not know and whom they often did not trust (Kvan, 1997). Furthermore, the operational role of the teacher continued to be central to the educational process and, in some cases, it was even strengthened as tutors became responsible for facilitating and co- ordinating the online exchange as well. Studio processes also acquired an ever increasing dependency on computers that monopolized communication in daily routines, tutorials, or special occasions such as interim or final submissions and thus the distance between tutors and students persisted.

The advent of Web 2.0 technologies, established a more definitive sense of openness and it was not long before the focus shifted from the technology itself to the collaborative character of the design practices developed through these applications (Achten \& Beetz, 2009).The character of the use of the internet shifted from repository to 
interactive, while blogging gave users the unprecedented opportunity to communicate and exchange content freely. The web began to be considered as an actual source of knowledge that offered "very low-cost communications, information abundance and the development of active and autonomous agents" (Anderson, 2016, p.40-41). It became dominant in theories such as connectivism which claims that "learning can reside outside of ourselves" (Siemens, 2005) and in the extended versions of theories such as the communities of practice (CoP) and the communities of inquiry (CoI) both representative of a model of knowledge that is based on social collaboration. These theories were in fact revisited and revised after Web 2.0 technology invaded the educational domain to describe how the proliferation of open online resources and means of communication and exchange determined a new learning behavior for the web users. The Fully Online Learning Community (FOLC) model in particular, a systematic rethink of CoI, is characteristic of such an approach, claiming that by now knowledge is solely produced with social and cognitive presences, rendering the teaching presence obsolete (Blayone et al., 2017).

Web 2.0 technologies have enabled extreme learner autonomy through the creation of fully online learning models -a trend that culminated with Massive Open Online Courses (MOOCs) during 2008-2013. However, they also gave great impetus to other educational formats that had begun to emerge as early as the 1990's whose original scope was to facilitate distant education, such as blended learning. In more recent years, blended learning ceased to be considered solely as a vehicle for distance education and was gradually integrated into mainstream practices with a new aim: that of enhancing communication and collaboration (Picciano, 2014).

Although no single definition exists, blended courses are considered to be classes where "a portion of the traditional face-to-face instruction is replaced by web-based online learning" (BlendKit Course). Numerically, blending is estimated as a $30 \%$ to $79 \%$ fluctuation between $\mathrm{f} 2 \mathrm{f}$ and online environments (Allen et al., 2007, p. 5). Garrison and Vaughn (2008), p.13 consider blended learning as "the organic integration of thoughtfully selected and complementary face-to-face and online approaches" with the aim of enhancing engagement. McGee and Reis (2012), p.9 propose blending to be described as "instructor and learners working together in mixed delivery modes, to accomplish learning outcomes that are pedagogically supported and which bridge course environments in a manner meaningful to the learner."

Carman (2002), p.2 distinguishes five key ingredients to blending: live events; online content; collaboration; assessment and reference models. Bonk and Graham (2005), p.4, on the other hand, identify three types of blends: the enabling; the enhancing and, finally, the transforming blend. While the first focuses on accessibility issues, enhancing blends allow for incremental changes to pedagogy where additional resources may be included online. It is the transformative blend, however, that allows for a radical reconsideration of pedagogy toward "a model where learners are not just receivers, but actively construct knowledge through dynamic interactions."

Blended learning is "the inspiration of the innovation both pedagogically and technologically in higher education" (Vaughan et al., 2013, p. 9). In fact, as Ossiannilsson (2017), p.7 argues, "blended learning concerns mindset and pedagogy more than it does technology," so models developed from fusing multiple learning environments move towards a more student-centered competency-based model where "all learners could 
reach full potential" (p. 34). Kocaturk (2017), p. 2 argues that the integration of information technology into the specific context of the architectural studio has both a mediational and an instrumental dimension; the first allows learning to take place in formal as well as informal settings; the latter, allows for digital design media "to serve as a means or agency for generating disciplinary knowledge content.” Despite its benefits, however, blended learning has not yet been fully explored and exploited in design education (Pektas, 2012). Some experiments in this direction introduced the use of platforms such as MOODLE (Devetakovich et al., 2011) as centrally managed learning tools for the exchange of information between participants on a course. Some of the major benefits of the use of such educational platforms were,-amongst others,-facilitating the delivery of information, allowing remote participants to monitor the design process and making DS material accessible long after the end of the course (Salama, 2015).

In this line of inquiry, Pak and Verbeke built upon previous experience from urban design applications such as 'mycitylab' and 'spacehive' in order to create the concept of Design Studio 2.0 (DS2.0),named after the Web 2.0 technology from which it derived (Pak \& Verbeke, 2013). The Urban/Explorative Architectural Design Studio they created in 2012 and repeated in 2013 set the pace for DS2.0 by using a blog-like web setting whereby students were required to $\log$ in and contribute to the creation of a collective map of information regarding Luxembourg and Brussels respectively. This course setting aimed to extend the DS "to a shared and globally accessible virtual world creating novel potentials for collaboration." (ibid, p. 47).

The second important educational model that was significantly enhanced by web 2.0 was network learning. Goodyear originally defined network learning as being learning in which ICT is used to promote connections: between one learner and other learners, between learners and tutors; between a learning community and its learning resources" (Goodyear, 2005, p. 83).In this framework, ICT infrastructure is considered to enable connections across space and time and also between diverse contexts and situations (Bonderuo Dohn et al., 2018). Network learning pedagogical ideals are deeply affiliated with the social theory of the CoP and especially Jean Lave's Situated Learning theory, whereby learning occurs through "legitimate peripheral participation" and thus by immersion in the new community, absorbing its modes of action and meaning as a part of becoming a member of a sustained community of practice (Lave, 1991).

Network learning holds a broader perspective of knowledge creation between what is considered to be public knowledge as in theory, research and best practice; practitioners' knowledge and the knowledge created through collaborative work and enquiry (Jackson \& Temperley, 2006, p.6). This holds great potential in the rethinking of the DS as it challenges its implicit structure by establishing direct ties between learners and their professional community, decreasing the gap between academic knowledge and professional practice. Network learning offers many occasions for what Brown et al. (1989) call 'enculturation' without the shortcomings of traditional normative instruction and the mediation of a tutor. It allows informal exchanges between peers and it expands the notion of learning to both human and non-human actors. In fact, network learning, stated by Bonderuo Dohn et al., (2018): 35, could be equally supported by other means such as physical artifacts or artistic stimulation of senses and feelings.

The proliferation of social networking platforms gave way to the idea of connecting the VDS with services such as Facebook and YouTube that promote collaboration and 
sharing of user generated content. Ham and Schnabel's Social Networked Virtual Design Studio (SNVDS) course prerequisites asked the students to set up their own YouTube accounts in order to present their work in 8-10 min videos or to tap into their own 'social capital' by connecting via Facebook or Skype with other people so as to research information regarding an overseas site (2011).In one way or another, the coordinators of the SNVDS activated the students towards a new type of learning that made of the most of their capacity to navigate the web by immersing them even further into the subject matter. This was carried out mostly by selecting digital tools and integrating them strategically into the course format in order to increase student connectivity and to help them 'achieve higher levels of collective intelligence' (Ham \& Schnabel, 2011, p.412).

While blended learning explores the potential of the integration of online and off-line learning tools, networking focuses on the connectivity between the participants and the rest of the course resources within these modalities. Blending expands the field of interaction and networking determines the way participants will navigate the course. Both blended and networked models applied in architectural education challenge DS operational modes and redistribute power among participants by assigning learners' with greater autonomy in a way that original VDSs had not.

\section{Design studio redesign methodology}

With regard to these attempts, a new layout was articulated for the 9th semester urban design studio in the school of Architecture of the National Technical University of Athens (NTUA) with Professor N. Marda. This is the last studio before the graduation thesis and it is a very challenging endeavor whereby the students are confronted with the complexity or the city by working in controversial urban landscapes. The studio has approximately fifty students who are divided into groups of two or three. It lasts 13 weeks but is further increased by the Christmas holiday and exam break to 18 weeks.

Research on previous case studies and theories of blended and networked learning led to the consideration of a series of changes in the undergraduate DS format originally tested in a postgraduate course on urban design in NTUA that was carried out with Professors N. Marda and G. Parmenidis during 2014-2016. A blended model of operation was used as a means of delivering the course content both online and in-class in an asynchronous manner favoring the possibility that students watched the material prior to coming to class. This allowed them to critically engage with the discussions that were held every week and to gain control of their learning. In addition, blogging was used intensively in order to enable students to contribute to content formation and interact with one another. Learning analytics had shown that students had almost doubled their presence on the course as online attendance rates were consistently high throughout its duration. At the same time, a deeper involvement was expressed by the frequency of their blogging and the quality of the learners' posts. (Parmenidis et al., 2016).

The DS redesign presented in this paper describes an attempt to introduce these practices to a much larger cohort of undergraduate students who have never been exposed to experimental studio blended or networked delivery modes before. Therefore, compared to the previous experience the new layout for the undergraduate cohort was 
deliberately less ambitious in terms of asynchronous learning modalities but nevertheless oriented towards openness.

As far as blending is concerned, the redesign sought to establish multiple learning environments in the physical and virtual space. This meant that an online component was introduced in the studio in order to ensure a parallel online presence for all participants as an open space for possible encounters, "a cluster of more or less loosely associated participants and resources and ideas" (Downes, 2017, p.146). F2f sessions were thoroughly revised and rearticulated to support these practices, as modalities (online and off-line) would need to work as complementary to one another. Tutors used versal.com to upload their educational resources, while student groups designed their blogs in tumblr, weebly, wordpress and wix. Tutor and student content was disseminated in the form of YouTube videos, links to open resources, material related to the site area, references to similar projects, digital or physical models of design research and artifacts, etc. (Fig. 1, right).

Physical activities on the other hand, -besides the regular weekly meetings between tutors and students, - included open discussions, regular presentations of student work and encounters with people related to the project area who visited the studio in class (Fig. 1, left). A series of workshops were also realized in the project area and were carried out by the studio's external collaborators, mostly artists. During all these activities, the students were required to perform as a group or contribute as groups to the rest of the class in some way. These exercises were intended to activate them as agents of a wider network and to instill the idea and the ethics of open collaboration.

In this framework, multiple communication channels were established between peers, tutors, stakeholders and experts in order to promote the belief that information and knowledge are distributed over an extensive network of resources and people. The new layout aimed to limit phenomena of autocratic behavior by opening up the process of content formation to students and all other interacting agents in the studio process as well. "The integration of specific knowledge from different domains is essential for the design studio implementation as well as other problem solving types of education" claim Prins \& Heintz (2009, p. 38).

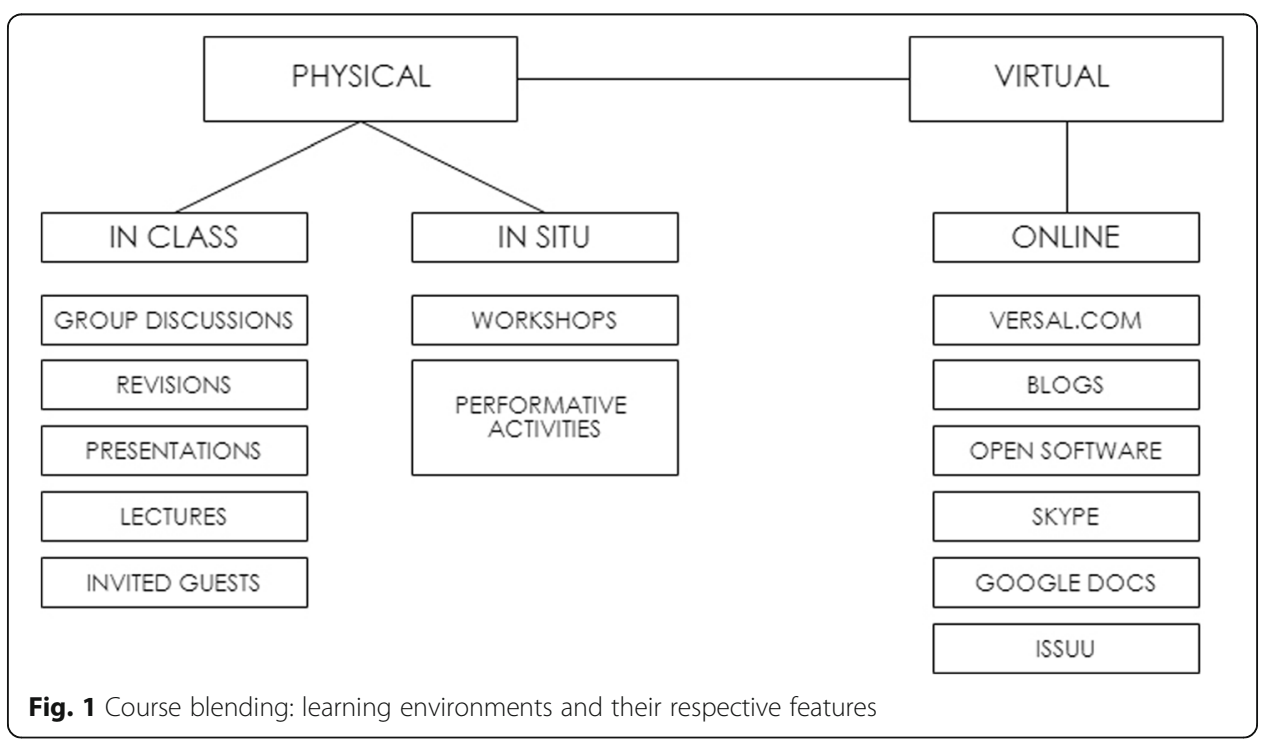


All activities in one way or another were knitted as a web (Fig. 2) and brought together students, the community and people from different domains in order to create the synergies necessary for the collection and management of all related information. The network structure of the studio traversed all types of activities not just those that took place in the online component. Students were not required to engage with all learning environments equally, but instead to choose their own degree of engagement according to their personal preferences.

\section{Studio impact results}

The documentation of all activities and their consequent transformation into digital material uploaded in the form of posts allowed for the close monitoring of content exchange throughout the 18 weeks of the studio's duration up until the date of submission. A series of data was retrieved both from versal.com analytics and the student blogs in order to evaluate the studio performance in terms of openness. The versal.com data -received daily in the form of a cvs data sheet via e-mail- included the date and time from student logins and the units they visited each time they logged in. Monitoring permission was granted by students themselves at the beginning of the course. Students, on the other hand, were asked to install statistics applications that registered the number of visitors and their respected views and to submit a report at the end of each month.

A survey was conducted upon the studio's completion as well; of the 50 students of the cohort, $33(66.0 \%)$ have submitted their answers on a series of issues regarding all studio activities through all learning environments. Students gave their insights regarding openness and rated the various features of the studio that aimed to promote open modalities together with any additional communication tools in terms of their effectiveness. The survey was divided into four parts and most answers were measured using a

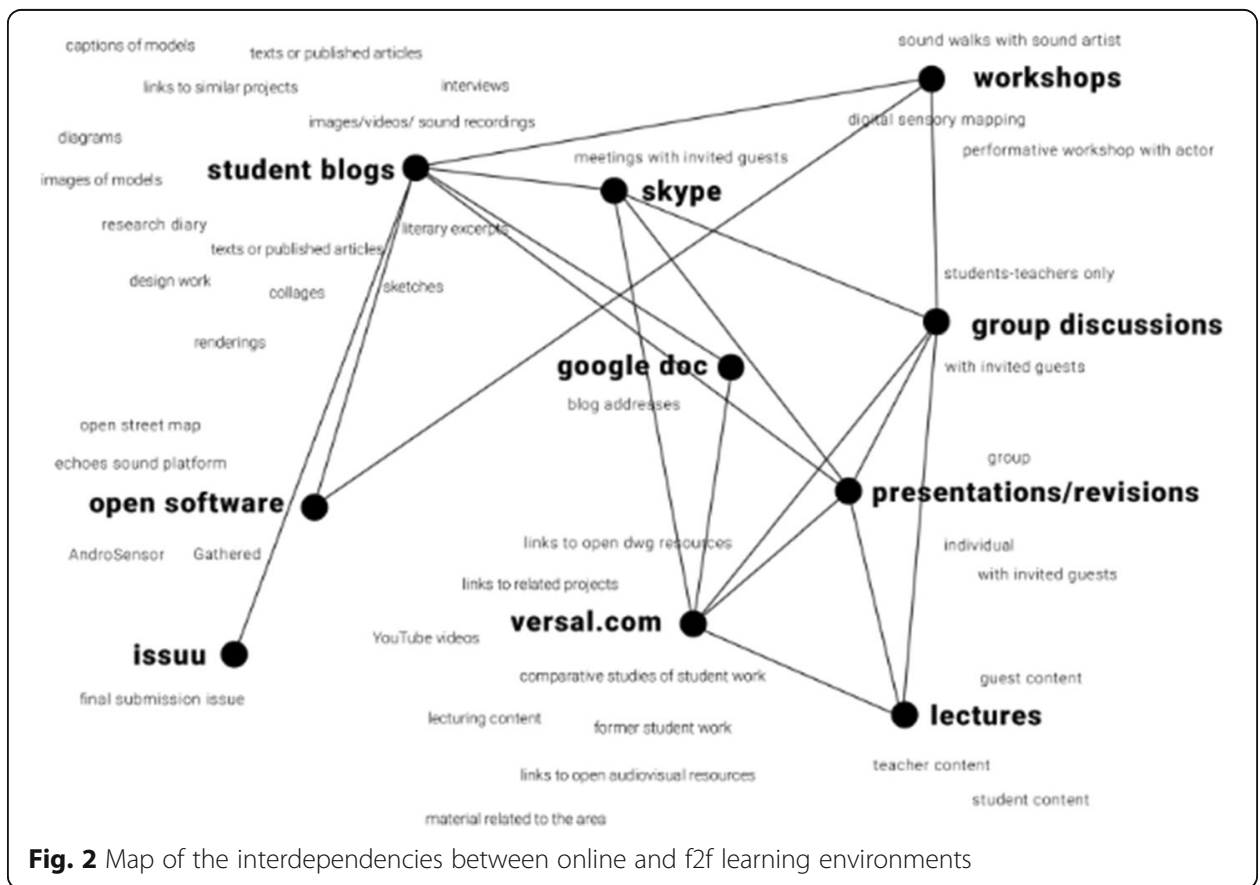


seven point likert scale, but there were also questions that required the students to give their opinion using their own words.

The first part asked the students to evaluate the various online components of the course. There were three different questions where students were asked to evaluate the content's contribution to learning, how interesting they thought it was and also how difficult it was for them to comprehend it. Another four questions asked them to evaluate the design of the online content units; the use of the versal.com platform in terms of easiness and synchronicity to the rest of the class activities; the use of blogging as a tool for presentation and monitoring others, and finally the articulation of the course material online in terms of relevance and duration. The second part of the survey focused on the time spent online. Students were asked to answer how often they visited versal.com and their peers' blogs, as well as the approximate amount of time they spent watching tutor or peer content. They were also asked to assess the time they spent online and provide their most preferable locations for watching the online content. In this section of the survey students needed to choose among different time frames and simply tick the box that corresponded to their average time spent online. The third part of the survey was dedicated to the evaluation of interaction. Students were asked to assess group discussions, blog monitoring and also English as a second language. They were also asked to evaluate the contribution of tutors, peers and guests to their learning experience. The fourth and last section asked them to comment on their overall experience using their own words: what was their most and least preferable part of the course and even make suggestions about what could improve their learning experience. Students were also asked to rate the course's hybrid character as well as their overall experience and to say whether they would like to keep visiting the online content after course completion.

\section{Content}

The studio was designed to be an open system of resources; the more the students engaged in design research, the more information they shared and the more the network grew. The transformation of information and knowledge into small digital modules, such as blog posts, facilitated this exchange and helped capitalize on all recorded and documented digital and in-class communication.

Content formation was distributed to both tutors and students; teaching content was spread during the semester into seven distinct units (weeks 01, 02, 03, 05, 07, $08,12)$ most of which were uploaded in regard to the studio's progression and the students' design production and not on prefixed dates. Tutor material included around 50 sub-units of lecturing material, links to interesting projects, examples of mapping and design methodologies, audio visual material related to the area, presentation of projects of urban regeneration and also former student work in the form of video presentations or links to online documents. The ability to sum up all student material at critical points in the design process and to use them cumulatively or comparatively was also exploited, -especially during the early stages of research, - as it offered the opportunity to collect all student content into one unit available to all for further use and to treat this material as a common resource. Thus, there were occasions when the tutors capitalized on student content and posted in on versal.com for anyone to see. 
Student blogging, on the other hand, started as early as the beginning of the course by all 19 student groups and was used throughout the duration of the course as a means of presenting student work for revisions and during interim submissions. Changes in the layouts were noted during the semester as students adjusted the blog articulation to fit in their content accordingly. Student content reached around 450 blog posts of which more than 300 were original student work. Student posts varied in number and in type as the groups followed diverse approaches to research and design and a completely different rate of transmission. Posts exist with plain text with observations and comments, or excerpts of literature, numerous cartographic attempts, recorded sounds, photos or videos, collages, descriptions of their encounters with locals and interviews, links to projects they considered relevant to their assignment and the progress of their design projects as they evolved through time. Interestingly, many of the students used blogs as diaries where they regularly posted elements from their research or their day-to-day activities and impressions of the area. Student blogging activity varied according to each student team. Fig. 3 illustrates the number and the type of the posts published by two different representative student groups: despite that both teams used multiple types of posts; the left team (trg) has published significantly less (Fig. 3).

\section{Participation}

Participation levels in the online component varied throughout the various stages of the studio's progression. While there were students who kept a consistent online presence throughout the studio's duration by logging in to versal.com and frequently uploading on their blog, others were less keen to attend online and mostly used their blogs to present their design material around the dates of interim submissions. Blog activity indicates that half of the posts were made in October (49\%) and another $28 \%$ during November, that is to say during the first two months of the studio. These rates demonstrate how blogging gradually decreased as design proposals were formulated and students focused more on their team projects. Attendance rates in versal.com also attest to this fact: students were mostly active online during the first half of the total studio duration, with almost $20 \%$ of the total logins occurring during week two. This is not the case, however, for the blog monitoring activity, where passive attendance

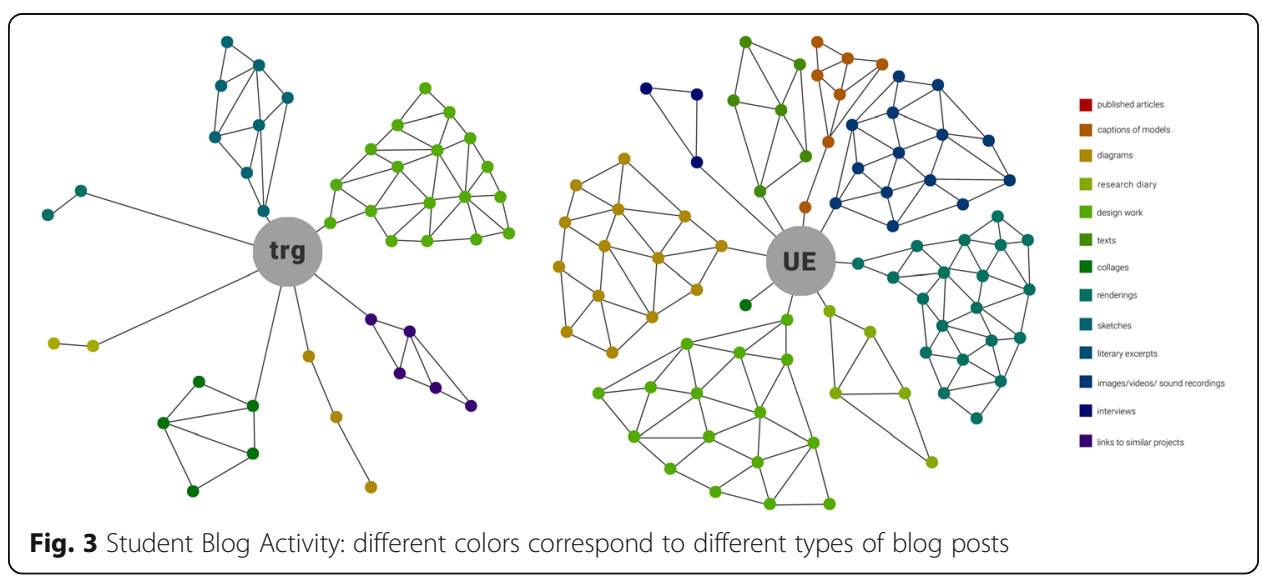


continued to be high throughout the duration of the studio. Online attendance did not affect the in-class one; instead, in-class attendance rates were consistently high throughout the 18 weeks.

\section{Types of interaction}

There were many types of interaction: tutor to student; student to student; student to experts; students to community. Group discussions and revisions were held in class, as well as some meetings with experts or people involved in the project area. In-situ activities involved interaction with artists. A sound artist and an actor worked with the students in the area. Online interactivity mostly included content sharing and monitoring one another, as well as a few video conferencing sessions with collaborators from abroad.

\section{Data on interactivity}

Numerical data were retrieved from analytics and blog statistics, while the survey also provided student insights.

As far as interaction was concerned, of the 33 students who took the survey, 13 (39.4\%) of them stated that they visited versal.com at least twice a week and17 (51.5\%) students stated that they did so at least once a week. Two (6\%) students admitted to logging in on a daily basis. Data collected from versal.com analytics confirm this activity, especially at the beginning of the studio activity when most content was uploaded.

When asked how often they visited their peers' blogs, 23 (69.6\%) professed to logging in at least once a week, $9(27.2 \%)$ of them said they did so twice a week and only two (6\%) students admitted to never following their peers' blogs. Statistics retrieved from the student blogs show a regular number of visitors per month -usually 20 to 40 distinct visitors per blog- with at least 70 page views per month. The more popular ones reached more than 200 monthly page views. Statistics from a particular team show a record of 798 page views in a single month.

When students were asked to comment on their experience in terms of interaction by writing down their own thoughts, 8 out of 33 students (24.2\%) stated that their most preferred activity was group revisions via blogs. In the overall rating of interaction, students rated live group discussions with an average of 5.85, blog interactivity with an average of 5.65, interaction with guests with an average of 4.8 and peer contribution with an average of 5.94 .

\section{Discussions}

Blending the studio was a choice that intended to encourage greater learner autonomy, while networking sough to promote student collaboration and active engagement. The studio format provided the framework and the students were free to choose their mode of interaction and degree of engagement.

Blog post monitoring, as well as the answers collected from the survey, revealed that the students mixed the course features in a completely different manner and that each one chose a personal mode of attendance within the limits of what was originally planned for the course. Thus, blending in this case is definitely attributed more to learning rather than teaching, as Daniel (2016) would argue-at least at course level-, in 
so far as instruction planning can only do as much as make these features available and then let students decide upon which one to adopt. The students themselves will eventually carry out the blending of these tools and control how they immerse themselves into their own learning experiences.

In the beginning of the course some students found its open layout unsettling or felt intimidated by the skills needed to support it; blog creation, online attendance to name but a few. The multiplicity of resources and the recurring conflicts between different agents were sometimes confusing and difficult to manage, let alone within such a tight timeframe. In situ workshops also presented students with a great challenge as they required an extensive physical presence within a rather controversial area and an unprecedented intimacy in working with others.

Some students also expressed their skepticism at the beginning of the course with regard to the openness and the transparency of the design process for fear that eventually design solutions would lack originality and would all look alike. This persistence upon the notion that ideas are unique and that they needed to protect their ideas from theft was dissolved as soon as the first groups started uploading products of their design work and research. This was a critical point because it became clear that even in cases where students used the same data, their approaches to design and representation were in fact quite different. From that point onward they started trusting the format and feeling more secure.

Tutors were also required to have a high level of digital literacy and spend more time in designing and overseeing all processes. There was a constant monitoring of blog activity and online attendance; workshops were scheduled outside the regular course dates in order to ensure that students would be able to witness events held on different days of the week in the area. This layout required alertness and flexibility; new resources were added according to the emerging student preferences and student work was regularly collected and used as reference material in group discussions.

When asked to comment on which part of the course was most appealing to them, students gave a variety of responses. Online lectures were highly appraised (30.3\%), as well as group revisions (21.2\%), discussions $(15.1 \%)$ and the use of blogs (15.1\%). Interestingly, some of the most preferable course components for some students were the least preferable for others. Blog presentations in particular, were rated most and least preferable by the same percentage (27.2\%). Another $21.2 \%$ of the students who took the survey insisted that there were no changes needed in the format. In fact, when asked directly what component they would like to completely omit from the course all 33 (100\%) students answered "nothing."Despite not liking some components as much as others students still considered them of some value in the overall layout.

It is also interesting to note that even students from the same group felt differently about the various features of the studio, giving the most contradictory answers to the questions being asked. Out of the 33 students who took the survey, analysis showed an equal number of different blending formats and learning paths. Fig. 4 shows the ratings - on a scale of 1 (least preferred) to a scale of 7 (most preferred) - of four students for six different course components. These ratings are also representative of the personal blending mix each student has configured for himself/herself according to his/her preferences. 


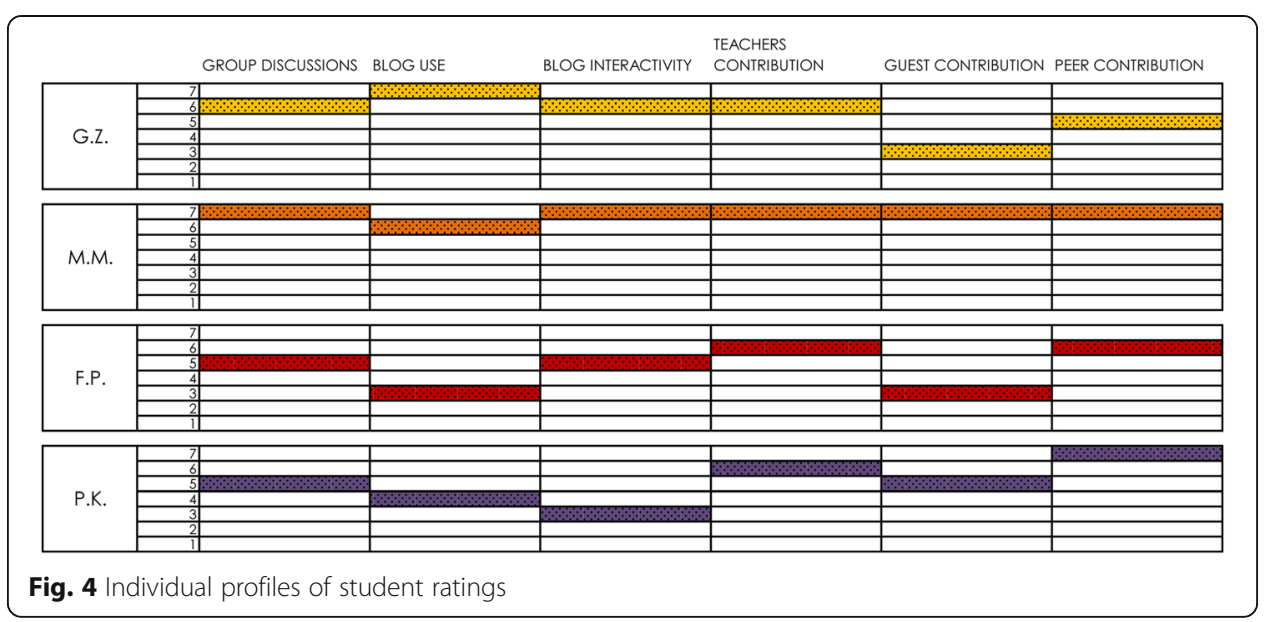

In this context, studio blending can be conceptualized as being a set of open resources and open modalities and networking as being a set of various communication features made available to all students or even suggested by students themselves without prescribing the manner or the extent of their use. There can be an unlimited number of studio attributes, but the degree of student involvement in each one of these will always be subject to their own individual preferences. Figure 5 shows a list of indicative course properties as in different tools of communication and various resources while the diagram above represents an evaluation chart using a scale from 1 to 7 to characterize the degree of student engagement ( 1 less involved-7 most involved).This is a tool that can be used both to collect data from individual participants or the tutors and also to express the cohort's collective preferences. Each time the studio runs, new data will be collected by the participants individually which will determine the dominant resources and the modalities most visited. The deciphering of this information is a grounded theory approach that can then be used

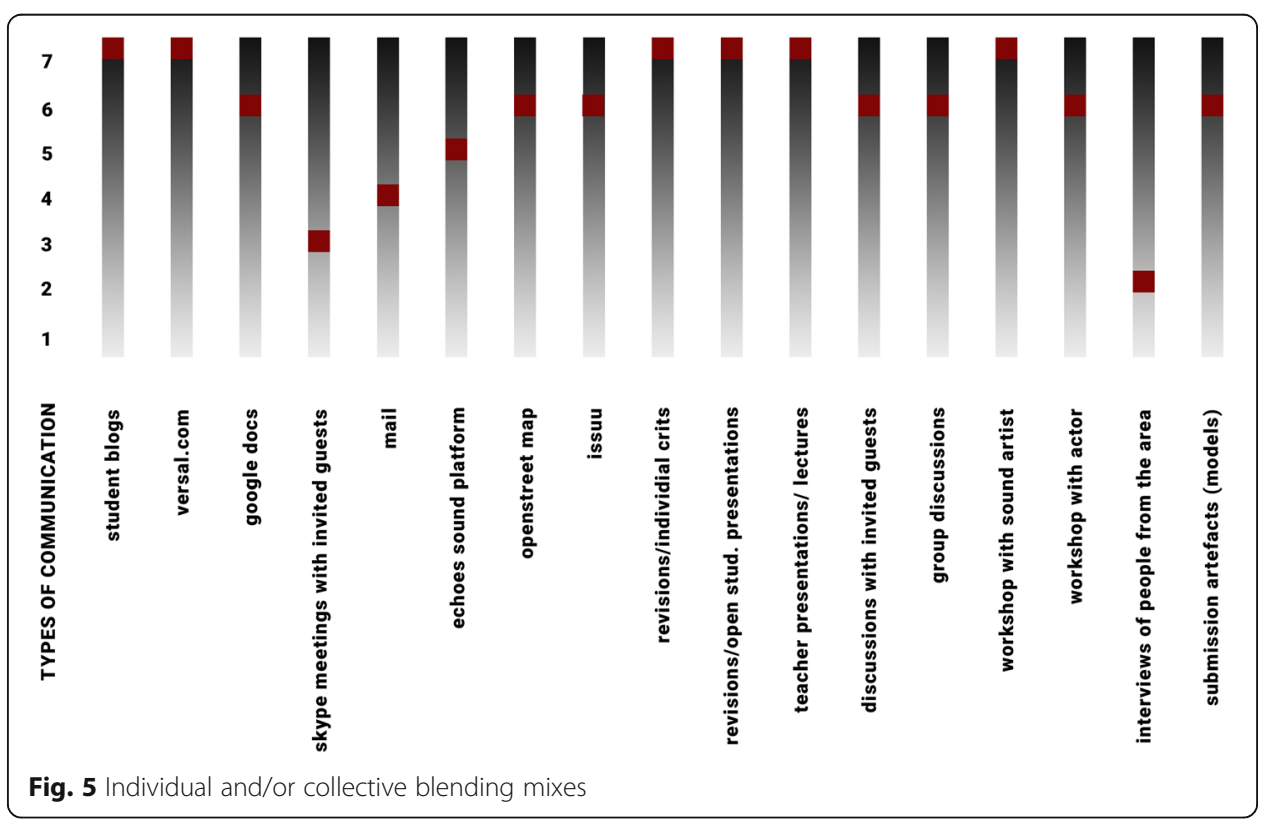


by tutors as a tool for evaluating the studio layout and its features, but also as a guide for reprogramming the studio for the next time it runs.

\section{Conclusions}

Blending and networking practices secure relevance and continuity between academia and the profession by establishing a culture of research in the design studio. In the light of increasing demands placed upon the profession, providing students with multiple resources and a means of managing the information becomes an essential task. In fact, the complexity of the urban phenomena and the rapidly changing socio-economic dynamics in contemporary cities mostly make up for ill-defined, indeterminate problems which call for much greater flexibility in working with others and the constant acquisition of new skills and competences. These qualities are necessary for the contemporary designers determining not just a possible solution to a problem but -most often- the problem itself.

Nurturing research and collaboration increases students' awareness of the contemporary realities and provides them with different ways of coping. Blended, networked studio formats offer students the possibility to extend their knowledge base and interact not only with their peers but also with the community. Through interviews and meetings with various project stake-holders, students get the chance to obtain the information they need directly from a source. This approach to learning requires participants to critically engage with dialectical practices and to discuss their views openly in communities of people who share an interest in the subject. Becoming accustomed to working in an open collaborative manner in the studio disseminates this way of perceiving architectural design as being a process that is completely interrelated with the place and the people it addresses. It also highlights the importance of working in groups and sharing resources with people from the same profession or other disciplines.

In signature pedagogies, such as the DS, the way in which a studio runs is similar to how an office operates. Opening up the educational process to more stakeholders and enhancing collaboration is not simply a pedagogical trend, but it is directly related to how the contemporary professional activity is perceived. Thus, blending and/or networking does not only affect the educational experience but it also sets a new framework for design practice as well. There is an important distinction to be made, however, in that the integration of blended practices in the DS does not arise from a need to mirror professional practice to design education; instead, it aims to promote the notion of the individual learner as a life-long learner who is always interrelated with others and thus interdependent (McClean, 2009). Seen in this context, blending pedagogy is used to promote openness as in agency and expansion and as in the practice of forming key relationships, not design solutions. It provides learners with a way to be and also to be with others, therefore contributing to a more holistic approach towards the design process.

\footnotetext{
Abbreviations

Col: Communities of Inquiry; CoP: Communities of Practice; CSCW: Computer Supported Collaborative Work; DS: Design Studio; DS2.0: Design Studio 2.0; f2f: Face-to-face; FOLC: Fully Online Learning Community; MOOCs: Massive Open Online Courses; NTUA: National Technical University of Athens; SNVDS: Social Networked Virtual Design Studio; VDS: Virtual Design Studio
} 


\section{Funding}

This research is part of the author's PhD Research funded by the NTUA special account research fund in the form of a scholarship.

\section{Availability of data and materials}

The datasets generated and/or analysed during the current study are not publicly available due to the fact that they are part of an ongoing PhD research but are available from the corresponding author on reasonable request.

\section{Authors' contribution}

I have approved the manuscript for submission.

\section{Competing interest}

The author declares that she has no competing interests.

\section{Publisher's Note}

Springer Nature remains neutral with regard to jurisdictional claims in published maps and institutional affiliations.

Received: 28 June 2018 Accepted: 4 December 2018

Published online: 24 December 2018

\section{References}

Achten, H.H. \& Beetz, J. (2009). What happened to collaborative design? In G. Cagdas, C. Gulen (Eds), Computation: The new realm of architectural design. In Computation: The New Realm of Architectural Design: 27th eCAADe Conference Proceedings, 357-366. eCAADe: Conferences. Istanbul: Istanbul Technical University, Faculty of Architecture. Retrieved from: https://cumincad.architexturez.net/doc/oai-cumincadworks-id-ecaade2009-123.

Allen, E. I., Seaman, J., \& Garrett, R. (2007). Blending. In The Extent and Promise of Blended Education in the United States. US: The Sloan Consortium (Sloan-C).

Anderson, T. (2016). Theories for Learning with Emerging Technologies. In G. Veletsianos (Ed.), Emergence and Innovation in Digital Learning: Foundations and Applications. Edmonton: Athabasca University Press.

Bachman, C., \& Bachman, L. (2010). Self-identity, rationalization and cognitive dissonance in undergraduate architectural design learning. arq: Architectural Research Quarterly, 13.2(4), 315-322.

Blayone, T., van Oostveen R., Barber, W., Di Giuseppe, M. \& Childs, E. (2017). Democratizing digital learning: theorizing the fully online learning community model. In International Journal of Educational Technology in Higher Education14:13 (2017). doi:https://doi.org/10.1186/s41239-017-0051-4

BlendKit Course: BlendKit Reader: Chapter 1, Understanding Blended learning 3rd edition, Linda Futch, Baiyun Chen (Eds.) Retrieved from: https://blended.online.ucf.edu/blendkit-course-blendkit-reader-chapter-1/

Bonderup Dohn, N., Sime, J.-A., Cranmer, S., Ryberg, T., \& de Laat, M. (2018). Reflections and challenges in networked learning. In N. Bonderup Dohn, S. Cranmer, J.-A. Sime, M. de Laat, \& T. Ryberg (Eds.), Networked Learning - reflections and challenges (pp. 187-212). Switzerland: Springer. Research in networked learning. https://doi.org/10.1007/978-3-319-748573_11.

Bonk, C., \& Graham, C. (2005). Handbook of blended learning: Global perspectives, local designs. San Francisco, CA: Pfeiffer Publishing.

Bradford, J.W., Cheng N. YW \& Kvan, Th. (1994). Virtual design studios. In T. Maver, and J. Petric (Eds.) The Virtual Studio. Paper presented at the proceedings of the 12th European conference on education in computer aided Architectural Design, 7-10 September 1994, Glasgow, (pp. 163-167).

Brown J.S., Collins, A., Duguid, P. (1989). Situated cognition and the culture of learning. In Educational Researcher, Vol. 18, no 1, pp. 32-42, Jan-Feb 1989

Buchanan, P. (2012, September 28). The Big Rethink: Rethinking Architectural Education. Architectural Review. Retrieved from https://www.architectural-review.com/8636035.article?search=https\%3a\%2f\%2fwww.architectural-review. com\%2fsearcharticles\%3fparametrics\%3d\%26keywords\%3dthe+big+rethink\%26PageSize\%3d10\%26cmd\%3dGoToPage $\% 26$ val\%3d5\%26SortOrder\%3d1

Carman, J.M. (2002). Blended Learning Design: Five Key Ingredients. In Agilant Learning, retrieved from: http://blended2010. pbworks.com/f/Carman.pdf

Crowther, P. (2013). Understanding the signature pedagogy of the design studio and the opportunities for its technological enhancement. J Learn Design, 6(3), 18-28.

Daniel, J. (2016). Making Sense of Blended Learning: Treasuring an Older Tradition or Finding a Better Future? Contact North | Contact Nord, 24th February 2016. Retrieved from https://teachonline.ca/tools-trends/blended-learning-successful-designdelivery-and-student-engagement/making-sense-blended-learning-treasuring-older-tradition-or-finding-better-future

Devetaković, M., Arsić, P., Nikolić, l., Petruševski, L., \& Mitrović, B. (2011). Integration of e-learning concepts in urban design studio: The case of a virtual learning environment supporting a specific educational mode. In Paper presented at the Proceedings of the YU Info 2011 Conference, (pp. 26-32). Kopaonik: Serbia: Information Society of Serbia.

Downes, St. (2017). Toward Personal Learning: Reclaiming a role for humanity in a world of commercialism and automation. Retrieved from: http://www.downes.ca/post/67018

Dutton, Th. (1987). Design and studio pedagogy. J Architect Educ 41(1). (Autumn, 1987), 16-25. Retrieved from http:// itecideas.pbworks.com/f/Dutton-design+and+studio+pedagogy.pdf

Garrison, R., \& Vaughan, N. D. (2008). Blended learning in higher education: Framework, principles, and guidelines. San Francisco: Jossey-Bass.

Goodyear, P. (2005). Educational design and networked learning: Patterns, pattern languages and design practice. In Australasian Journal of Educational Technology, Vol. 21, 1, pp. 82-101 
Griegson, H. J. (2004). The internet as a tool for communication in design projects. CEBE Transactions, 1(2), 77-90. https://doi. org/10.11120/tran.2004.01020077.

Ham, J. J., \& Schnabel, M. A. (2011). Web 2.0 virtual design studio: Social networking as facilitator of design education. Architect Sci Rev, 54(2), 108-116. https://doi.org/10.1080/00038628.2011.582369.

Jackson, D., \& Temperley, J. (2006). From professional learning community to networked learning community. In Proceedings of International Congress for School Effectiveness and Improvement (ICSEI) conference 2006. Fort Lauderdale: January 3rd 6th 2006.

Kocaturk, T. (2017). A socio-cognitive approach to knowledge construction in design studio through blended learning. In Journal of Problem Based Learning in Higher Education (JPBLHE), 5, 1, 1-21

Kvan, T. (1997). Studio Teaching without Meeting: Pedagogical Aspects of a Virtual Design Studio. In Y.-T. Liu, J.-Y. Tsou, \& J.H. Hou (Eds.), CAADRIA '97, Proceedings. Paper presented at the Proceedings of the Second Conference on Computer Aided Architectural Design Research in Asia, 17-19 April 1997, (pp. 163-177). Hsinchu: National Chioa Tung University.

Laiserin, J. (2002). From atelier to e-telier: Virtual design studios. Architectural record | Digital Practice | Digital Architect, January 2002, the McGraw Hill companies. Retrieved from: http://papers.cumincad.org/data/works/att/3a28.content.pdf

Laurillard, D. (2012). Teaching as a design science: Building pedagogical patterns for learning and technology. New York: Routledge.

Lave, J. (1991). Situating learning in communities of practice. In L. B. Resnick, J. M. Levine, \& S. D. Teasley (Eds.), Perspectives on socially shared cognition (pp. 63-82). Washington, DC: American Psychological Association. https://doi.org/10.1037/10096-003

Masdeu, M., \& Fuses, J. (2017). Reconceptualizing the design studio in architectural education: Distance learning and blended learning as transformation factors. ArchNetiJAR: Int J Architect Res, 11(2), 06-23 Retrieved from: http://www.archnet-ijar. net/index.php/IJAR/article/view/1156/pdf.

McClean, D. (2009). Embedding Learner Independence in Architecture Education: Reconsidering Design Studio Pedagogy. PhD Dissertation: The Robert Gordon University.

McClean, D., \& Hourigan, N. (2013). Critical dialogue in architecture studio: Peer interaction and feedback. Journal for Education in the Built Environment, 8(1), 35-57.

McGee, P., \& Reis, A. (2012). Blended course design: A synthesis of best practices. J Asynchhronous Learn Networks, 16(4), 7-22.

Novakova, K., Achten, H., Treyer, L., Schmitt, G., \& Moravec, S. (2012). For students: Sketching apart together: A collaborative seminar focused on architecture studio education. In H. Achten, J. Pavlicek, J. Hulin, \& D. Matejovska (Eds.), Physical Digitality: Proceedings of the 30th eCAADe Conference, Vol. 2. Paper presented at the 30th eCAADe ConferencePrague, 12-14 September 2012, Czech Republic: Czech Technical University in Prague, (pp. 77-85) Retrieved from: https://cumincad. architexturez.net/doc/oai-cumincadworks-id-ecaade2012-11.

Ossiannilsson, E. (2017). Blended Learning, State of the Nation. International Council for open and Distance Education Insight Paper, Retrieved from ICDE website: https://icde.memberclicks.net/assets/RESOURCES/ Blended\%20Learning\%20ICDE\%20Insight\%20Paper\%202017\%20compressed.pdf

Pak, B., Newton, C., \& Verbeke, J. (2012). Virtual worlds and architectural education: A typological framework. In H. Achten, J. Pavlicek, J. Hulin, \& D. Matejovska (Eds.), Digital Physicality Proceedings of the 30th eCAADe Conference, Vol. 1. Paper presented at the 30th eCAADe conference in Praque, 12-14 September 2012, Czech Republic: Czech Technical University in Prague, (pp. 739-746) Retrieved from: https://cumincad.architexturez.net/doc/oai-cumincadworks-id-ecaade2012-234.

Pak, B., \& Verbeke, J. (2013). Redesigning the design studio: Two learning experiments. Journal of Learning Design, special issue: Design Education, 6(3). https://doi.org/10.5204/jld.v6i3.160.

Parmenidis, G., Marda, N., Author, (2016). Omitted

Parnell, R.., (2001). It's good to talk: managing disjunction through peer discussion. Paper presented at the Architectural Education Exchange (AEE) Conference, Cardiff University, Cardiff.

Pektas, S. T. (2012). The blended design studio: An appraisal of new delivery modes in design education. Procedia - Social and Behavioral Sciences, 51, 692-697. https://doi.org/10.1016/j.sbspro.2012.08.226.

Picciano, A. (2014). A critical reflection of the current research in online and blended learning. In ELM Magazine, issue 4/ 2014 Retrieved from: https://www.elmmagazine.eu/articles/a-critical-reflection-of-the-current-research-in-online-and-blendedlearning/

Prins, M., \& Heintz, J. L. (2009). Knowledge integration in architectural education; the development of a dynamic E-learning environment. In K. Belloni, J. Kojima, \& I. Pinto Seppa (Eds.), Improving Construction and Use through Integrated Design Solutions CIB IDS 2009 Conference Proceedings. Paper presentedat the proceedings of the CIB IDS 2009 international conference, 10-12 June 2009, (pp. 37-51). Helsinki: Retrieved from: https://www.vtt.fi/inf/pdf/symposiums/2009/S259.pdf.

Salama, A. (2015). Spatial Design Education: New Directions for Pedagogy in Architecture and Beyond, Surrey. UK: Ashgate.

Shulman, L. S. (2005). Signature pedagogies in the professions. Daedalus, 134(3), 52-59.

Siemens, G. (2005) , April 5. A learning theory for the digital age [blog post]. elearnspace. Retrieved from: Http: http://www. itdl.org/journal/jan_05/article01.htm

Stevens, G. (1998). The favored circle: The social foundations of architectural distinction. Cambridge: MIT press.

Vaughan, N. D., Cleveland-Innes, M., \& Garrison, D. R. (2013). Teaching in Blended learning Environment: Creating and Sustaining Communities of Inquiry. Edmonton: CA: Athabasca University AU Press.

Yee, S., (2001). Building Communities for Design Education: Using Telecommunication Technology for Remote Collaborative Learning. Retrieved from DSpace@MIT 